\title{
Comparison and Categorization in the Development of Relational Similarity
}

\author{
Laura Kotovsky and Dedre Gentner
}

University of Illinois at Urbana-Champaign

\begin{abstract}
Kotovsxy, Laura, and Gentner, Dedre. Comparison and Categorization in the Development of Relational Similarity. CHILD DEvelopment, 1996, 67, 2797-2822. 4 experiments investigated the development of children's ability to recognize perceptual relational commonalities such as symmetry or monotonicity. In Experiment 1, 6- and 8-year-olds were able to recognize higherorder relational similarity across different dimensions (e.g., size/saturation) and across different polarities (e.g., increase/decrease), whereas 4-year-olds could recognize higher-order relational matches only when they were supported by lower-order commonalities (e.g., size/size but not size/saturation matches). Further experiments tested how the processes of comparison and categorization affected 4-year-olds' ability to recognize relational similarity. The results of the experiments supported the hypothesis that comparison and categorization processes lead to changes in children's representations of relational structure, enabling them to recognize more abstract commonalities. A computational model lent further support to the claims.
\end{abstract}

The ability to grasp relational similarity is fundamental to abstract thought. It underlies our appreciation of patterns of symmetry and mathematical structure and other subtle and elegant invariances. It allows us to makes analogies and apply inferences between superficially unlike domains. More important for cognitive development, the ability to perceive relational commonalities is fundamental to learning beyond the basic level. To understand relational categories such as predator or force-or even tool, weapon, or contract - the child must be able to process relational commonalities.

Thus the issue of when and how children become able to process relational similarity commands attention. The research on this issue has found considerable evidence suggesting a developmental change in children's ability to recognize relational similarity and use it in analogy and metaphor (e.g., Billow, 1975; Gentner, 1988; Piaget, Montangero, \& Billeter, 1977; Winner, Rosenstiel, \& Gardner, 1976). Accounts of this change can be divided into two camps: those who postulate a global change in children's cognitive processing and those who propose that changes in knowledge representation are sufficient to cause the relational shift.

Piaget and his colleagues argued for the global change explanation: specifically, that children achieve competence in relational similarity around the formal operations stage, at about 11 or 12 years of age (e.g., Piaget et al., 1977). This timing now seems unlikely in light of the growing body of research demonstrating early competence in relational similarity tasks. For example, Gentner (1977a) asked children and adults to carry out a mapping between two familiar domains, the human body and a tree. When asked, "If a tree had a knee where would it be?" 4-year-olds were as accurate as adults at pointing to the correct area of a picture. They were able to preserve the spatial relations among body parts, even when the task was made difficult by turning the pictures upside down or by adding misleading local details. Brown (1989) found that 2-year-olds could transfer a solution to a reaching problem by choosing a tool based on its functionally relevant properties (i.e., possessing a

Laura Kotovsky, Department of Psychology, University of Illinois at Urbana-Champaign; Dedre Gentner, Department of Psychology, University of Illinois at Urbana-Champaign (now at the Department of Psychology, Northwestern University). This work was supported by NSF grant no. BNS-9096259. The computational simulation was supported by ONR, contract no. N00014-89-J-1272. The authors would like to thank Mary Jo Rattermann, Judy DeLoache, Renee Baillargeon, and David Uttal for their insightful comments. We also thank Art Markman for his comments and assistance with the computational simulation. Last, we wish to express our gratitude to the parents and children who participated in the research. Correspondence concerning this article should be addressed to Dedre Gentner, Department of Psychology, Northwestern University, 2029 Sheridan Road, Evanston, IL 60208-2710.

[Child Development, 1996, 67, 2797-2822. (C) 1996 by the Society for Research in Child Development, Inc. All rights reserved. 0009-3920/96/6706-0042\$01,00] 


\section{Child Development}

hooked end). Finally, recent research using looking-time paradigms has suggested that even young infants are sensitive to identity relations (Tyrrell, Stauffer, \& Snowman, 1991). These kinds of results have led most researchers to adopt the knowledge-change view, that whether children can recognize relational similarity in a domain depends chiefly on their knowledge of that domain (Brown, 1989; Brown \& DeLoache, 1978; Brown, Kane, \& Echols, 1986; Carey, 1985, 1991; Chen \& Daehler, 1989; Chi, 1981; Chi, Feltovich, \& Glaser, 1981; Crisafi \& Brown, 1986; Gentner, 1977a, 1977b, 1988; Gentner \& Rattermann, 1991; Goswami, 1991, 1992; Goswami \& Brown, 1989; Ortony, Reynolds, \& Arter, 1978; Vosniadou, 1987, 1989).

However, showing that relational competence develops before the formal operations stage does not in itself prove the knowledge-change position. It remains possible that there is a global change in processing that occurs earlier than Piaget had proposed. Halford $(1987,1993)$ and his colleagues have taken this position, arguing that the relational shift occurs at around 4 years of age as the result of a maturational increase in processing capacity. Halford proposes that the degree of processing capacity required to carry out a match increases from objects to binary relations and finally to systems involving ternary relations. As evidence that processing capacity sufficient to process complex relational comparisons develops at around 4 years of age (Halford, 1987, 1992, 1993), Halford and his colleagues have shown gains at around this age in transitivity and class inclusion tasks. They have simulated this progression in the STAR model, a distributed connectionist system using tensor products (Halford et al., 1995). The current studies provide a test of these claims.

In this article we test a specific version of the knowledge-change hypothesis: Gent- ner's (1988) relational shift hypothesis, later amplified into what Gentner and Rattermann (1991) called the "career of similarity" hypothesis (see also Gentner \& Medina, 1996). This account posits that within any given domain $(a)$ overall similarity is the earliest and most naturally responded to (e.g., Rovee-Collier \& Fagen, 1981), and (b) the order in which partial matches come to be noticed is, first, matching objects, then matching relations, and finally matching higher-order relations. ${ }^{1}$ Our assumption is that this sequence is epistemological, not maturational: Children come to perceive similarity between objects (e.g., the likeness between a red apple and a red ball) before they perceive similarity among relations (e.g., the similarity between an apple falling from a tree and a spoon falling from a table); and appreciation of such lower-order relational similarity in turn precedes appreciation of higher-order relational similarity (similarity in relations between relations: e.g., the similarity between a squirrel swishing its tail and causing an apple to fall from a tree, and a toddler waving her arm and causing a cup to fall off the table). ${ }^{2}$

Gentner and Rattermann (1991) reviewed a large body of research that supports the relational shift hypothesis in that (a) the ability to perceive relational similarity appears later than the ability to perceive object similarity, and $(b)$ this relational insight appears at different ages in different domains (e.g., Billow, 1975; Brown et al., 1986; Bryant \& Trabasso, 1971; Chipman \& Mendelson, 1979; DeLoache, 1989, in press; Gentner, 1977a, 1977b, 1988; Gentner \& Toupin, 1986; Goswami, 1989; Pears \& Bryant, 1989; Rattermann, Gentner, \& DeLoache, 1989; Smith, 1984; Uttal \& DeLoache, 1995; Uttal, Schreiber, \& DeLoache, 1995). In particular, when relational similarity is pitted against object similarity, younger children are more influenced by object matches, and less able to attend to

${ }^{1}$ The relational shift is not a shift away from object similarity; even adults find it easier to process overall similarity (that includes object matches as well as relational matches) than to process pure analogy, and there is evidence that object matches are processed before relational matches (Goldstone \& Medin, 1994; Markman \& Gentner, 1996).

2 These levels of similarity are more precisely defined using a propositional representation. Attributes are defined as predicates taking one argument (e.g., BIG [a]), and relations as predicates taking two or more arguments (e.g., BIGGER [a,b]; Gentner, 1983, 1989; Palmer, 1975). The difference between first-order and higher-order relations is that first-order relations take objects or functions as arguments, and higher-order relations take propositions as arguments. That is, a higher-order relation is a relation between relations. Using this representation, object similarity involves a match at the level of attributes, lower-order relational similarity involves a match at the level of first-order relations, and higher-order relational smilarity involves a match at the level of higher-order relations. 
relational matches, than are older children (Gentner, 1988; Gentner, Rattermann, Markman, \& Kotovsky, 1995; Gentner \& Toupin, 1986). In this research we will test a more specific hypothesis: Within a domain the recognition of lower-order relational similarity precedes the recognition of higher-order relational similarity. We also test a second prediction of the relational shift hypothesis and other knowledge-based theories: namely, that increasing children's knowledge of domain relations should lead to greater sensitivity to relational similarity in the domain. This prediction was partially addressed in an experiment by Goswami and Brown (1989). They examined the effects of domain knowledge on analogy in preschool children using a picture-selection task, and found that children who could correctly complete a causal sequence tended to perform well on an analogy that utilized the same causal relation. A similar result was obtained by Gentner, Rattermann, and Campbell (1996).

However, although this finding is supportive of knowledge effects, it is not definitive. For example, it could be that highability children performed well on both the causal task and the analogy task. What is needed is a demonstration that providing children with knowledge about the domain can improve their performance on a relational similarity task. The chief goal of this research is to provide such a direct test: We ask whether learning the relations in a domain improves children's performance on a relational similarity task. A further goal is to propose and test a learning mechanism by which children can learn about domain relations from experience. This mechanism, which we call progressive alignment, is a crucial aspect of our proposal. In the progressive alignment mechanism, experiencing concrete similarity prepares children to perceive more abstract similarity without direct instruction. We elaborate on this mechanism later in the article. Our final goal is to test the role of relational language in promoting relational learning (Gentner \& $\mathrm{Me}-$ dina, 1996; Gentner \& Rattermann, 1991; Gentner, Rattermann, Markman, \& Kotovsky, 1995).

In choosing the domain for these studies we had two criteria in mind: (a) The domain should be familiar to preschool children, but at the same time, in order to permit a test of the knowledge-change hypothesis, there should be higher-order relations that preschoolers initially fail to perceive in similar- ity comparisons; and (b) the domain should be such that the similarity among higherorder relations can be manipulated independently from the similarity among objects and first-order relations. This requirement of separable kinds of similarity poses a methodological challenge. In natural experience, different levels of similarity are typically correlated (e.g., what looks like a tiger also has the causal powers of a tiger), and this correlation is often carried into experimental materials. For example, in Goswami and Brown's (1989) study of causal analogies, the correct completion of the $a: b: c:$ ?d analogy (i.e., the term " $d$ " such that the c,d causal chain matched the $a, b$ causal chain) often shared object-level similarity with the "c" term (e.g., tree: burnt tree stump::pile of leaves: ?burnt pile of leaves). A replication of this study separating object similarity and relational similarity produced many fewer correct responses (Gentner et al., 1996). Using materials in which multiple levels of similarity are present may lead to an inflated view of children's ability.

With these considerations in mind, we chose perceptual patterns as the stimuli for this research, because $(a)$ they permit independent manipulation of different aspects of the materials to address the problems of correlated attributional and relational similarity and $(b)$ they are familiar to children when presented in simple concrete depictions, but can prove challenging in more complex incarnations (e.g., Bryant, 1974; Chipman \& Mendelson, 1979; DeLoache, 1989; Goswami, 1989; Halford, 1987, 1992; Rattermann et al., 1989; Smith, 1984, 1989, 1993). In particular, Smith (1984) showed a relational shift in children's ability to copy simple dimensional relations, and Chipman and Mendelson (1979) showed a developmental increase in attention to symmetry in judging the complexity of perceptual stimuli. Adults and older children, but not 5-year-olds, judged patterns as less complex when they were horizontally symmetric, consistent with symmetry's serving as a higher-order organizing pattern. Thus, perceptual relations created from geometric forms met both of our criteria for stimuli design.

We used a triads choice task throughout the research. The child was shown three geometric figures, a standard and two choices, and was asked which of the choices the standard went with best. In each triad, the standard and the relational choice shared a higher-order relation, either symmetry or monotonicity (e.g., oOo and $\mathrm{xXx}$; see Fig. 
Same-Polarity

Same-

Dimension

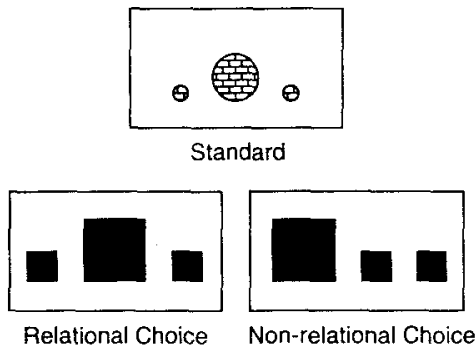

Cross-

Dimension

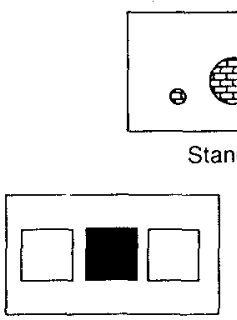

Relational Choice

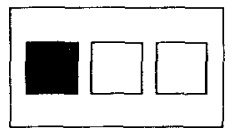

Non-relational Choice

\section{Opposite-Polarity}

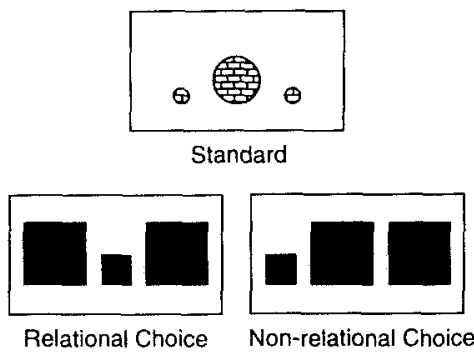

Relational Choice

Non-retational Choice

FIG. 1.-Samples of Same-polarity, Opposite-polarity, Same-dimension, and Cross-dimension stimuli types.

1). The elements that made up the standard were of different shapes and colors from the ones that made up the relational choice, so that its object-level similarity to the standard was low. The nonrelational choice, or foil, was created simply by rearranging the elements of the relational choice so as to break the higher-order relation, for example, oOo becomes ooO (see Fig. 1). This ensured that the foil and the relational choice were equally similar to the standard in their (low) level of object matches. Thus this test is a pure test of children's appreciation of relational similarity, since the advantage of the relational choice over the foil lies only in its relational commonalities with the standard.

We wanted to gauge children's ability to appreciate abstract higher-order relational similarity, as opposed to similarity based on first-order relational matches, or on both first-order and higher-order matches. Therefore, we varied the degree of first-order relational similarity that the relational choice shared with the standard (while keeping higher-order relational similarity constant). Two aspects of lower-order relational similarity were manipulated: dimension and polarity (see Fig. 1). Dimension concerns whether the dimension of change (over which the higher-order relation held) was the same in the standard and relational choice (i.e., whether the match was sizechange to size-change or size-change to saturation-change). Polarity concerns whether the direction of change was the same $(\mathrm{xXx} /$ $\circ \mathrm{Oo})$ or different $(\mathrm{xXx} / \mathrm{OoO})$ in the standard and relational choice. Varying polarity and dimension orthogonally led to four triad types varying in degree of match from most concrete to most abstract: for example, for the higher-order relation of symmetry, these are (1) Same-dimension, Same-polarity $(\mathrm{xXx} /$ oOo), (2) Same-dimension, Differentpolarity ( $\mathrm{Xx} / \mathrm{OoO})$, (3) Different-dimension, Same-polarity ( $\mathrm{xXx} / 121$ ), and (4) Differentdimension, Different-polarity-only the higher-order relation matches $(\mathrm{xXx} / 212)$. For adults, the higher-order relation match is sufficient. Even for case 4 (the bottom right cell of Fig. 1), adults virtually always choose the relational choice. Our first question was whether young children would perceive commonality based only on a shared higherorder relation.

The purpose of the first experiment was to test the predictions of the relational shift hypothesis and to establish a baseline of children's similarity processing against 
which to test our further hypotheses concerning mechanisms of learning. The predictions were that $(a)$ at all ages (barring ceiling effects), children would select the relational choice more reliably the more supporting commonalities there were (i.e., the more literally similar the relational choice was to the standard); (b) there would be a relational shift, such that older children would be better able to recognize higherorder commonalities in the absence of supporting lower-order commonalities.

\section{Experiment 1}

\section{METHOD}

\section{Participants}

Children were tested in ChampaignUrbana day-care centers, day camps, and public schools. There were 244 -year-olds (mean age 4-7, range $=4-1$ to 5-2), 24 6-yearolds (mean age $6-5$, range $=6-1$ to $7-2$ ), and 24 8-year-olds (mean age 8-6, range $=7-11$ to 9-7). An additional three 4-year-olds were tested but eliminated due to failure to meet the criterion for training and filler trials (see Procedure). All groups had equal numbers of males and females. The majority of the children in all of the experiments were white and from middle-class families. Systematic data on race and SES were not collected in these studies.

\section{Materials and Design}

The design was a completely randomized factorial mixed design with four between-subjects factors: age $(4,6$, or 8 years), polarity (same or opposite), sex (male or female), and order of presentation of stimuli (A or B); and three within-subject factors: dimension (same or different), higher-order relation (symmetry or monotonic-increase), and dimension of standard (size or saturation). Each child received 22 triads: 16 test triads, 2 training triads, and 4 filler triads.

Test triads.-The test triads consisted of a standard and two choices, a relational choice and a nonrelational choice. The standard and the relational choice always embodied the same higher-order relation, either symmetry or monotonicity. The nonrelational choice was created by permuting the objects that made up the relational choice. Each child received half monotonicity and half symmetry trials.

There were two key manipulations of the similarity between the standard and the relational choice: polarity (direction of change same or opposite) and dimension (di- mension of change: same dimension or cross-dimension), which were varied orthogonally to yield four match types, ranging from most concrete (Same-dim/Same-pol) to least concrete (Cross-dim/Opposite-pol) with two intermediate match types (Cross$\mathrm{dim} /$ Same-pol and Same-dim/Opposite-pol) (see Fig. 1).

The stimuli were constructed on $10.2 \times$ $15.2 \mathrm{~cm}$ index cards. The size-change stimuli were made up of two shapes, circles and squares of constant coloring (the squares were black and the circles had brick patterning as shown in Fig. 1). Each shape occurred in three sizes. The squares used to depict monotonicity were $1.6 \mathrm{~cm}, 2.5 \mathrm{~cm}$, and $3.8 \mathrm{~cm}$. The squares used to depict symmetry were $1.6 \mathrm{~cm}$ and $3.8 \mathrm{~cm}$. The circles used to depict monotonicity were $1.0 \mathrm{~cm}, 1.6$ $\mathrm{cm}$, and $2.8 \mathrm{~cm}$. The circles used to depict symmetry were 1.0 and $2.8 \mathrm{~cm}$.

The saturation-change stimuli were constructed using Chromarama colored paper. They were made of squares and circles of constant size (the squares were $3.8 \mathrm{~cm}$ and the circles were $2.5 \mathrm{~cm}$ ). There were two colors, red and blue. Each color occurred in three saturations (produced by the addition of white). The reds used to depict monotonicity were numbers 6141,6145 , and 6149 . The reds used to depict symmetry were numbers 6141 and 6149 . The blues used to depict monotonicity were numbers 6321 , 6325 , and 6329 . The blues used to depict symmetry were numbers 6321 and 6329 .

Training triads.-Children received two training triads designed to demonstrate easily the matching game; the child matched identical animals. For example, in one of the training triads the child had to indicate that an elephant "goes with" an identical elephant and not with a butterfly.

Filler triads.-There were four filler triads depicting simple geometric figures that shared object-level as well as lower-orderrelational and higher-order-relational similarity. These were designed to be very easy, both to boost the child's confidence and to check whether the child was on task. For example, in one filler triad the child had to indicate that three large ovals "go with" three small ovals and not with two ovals and a square.

\section{Procedure}

After the two training triads, the 16 test triads were presented in one of the two semirandom orders (random except for the 


\section{Child Development}

stipulation that there be no more than two of the same triad type consecutively). Each figure in a triad was presented on a separate index card. The cards were presented on a game board with four slots for index cards (see Fig. 2). The experimenter placed the two choice cards in the two top slots and put the standard card in front of the child, asking, "Do you know where that one [the standard] goes best?" Children could indicate their choice either by pointing to one of the two alternatives or by putting the standard card in the slot under their choice. No feedback was given on the test trials.

The four filler trials were spaced evenly through the study. During these trials the children were given general encouragement, such as "I like how you are playing this game. You look at all the pictures carefully and choose the best match." To be sure that children were on task we eliminated children who made more than one incorrect response on the training and filler trials.

\section{Preliminary Analyses}

Preliminary analyses including the factors of sex and order of presentation of the stimuli revealed no significant main effects and no significant interactions involving these factors. The data were therefore collapsed across these factors in subsequent analyses.

\section{Results}

The results are shown in Table 1 . As predicted, there was a relational shift: 4year-olds responded relationally on $53 \%$ of the test triads, 6-year-olds on $78 \%$, and 8year-olds on $90 \%$. Also as predicted, children chose more relationally when firstorder as well as higher-order relations matched. A $3 \times 2 \times 2$ (age $\times$ polarity $\times$ dimension) ANOVA with dimension as a within-subject factor revealed a main effect of age, $F(2,66)=55.08, p<.0005$, and main effects of polarity, $F(1,66)=7.67, p<.01$, and dimension, $F(1,66)=16.01, p<.0005$. Children chose the relational choice more often on Same-polarity triads, $M=78 \%$, than on Opposite-polarity triads, $M=70 \%$ (see Fig. 3), and more often on Samedimension triads, $M=79 \%$, than on Crossdimension triads, $M=69 \%$ (see Fig. 4). This was true at all ages. There were no reliable interactions involving age. As predicted, even the 8-year-olds were more likely to choose relationally when the higher-order match was supported by common first-order relations.

Consistent with the prediction that higher-order similarity emerges later than first-order similarity, the 4-year-olds showed above-chance levels of relational responding only when there was maximum lower-order relational support for the higher-order commonality: that is, in the Same-dim/Same-pol condition: $M=68 \%$, chance $=50 \% ; t(11)$ $=3.4, p<.01$; all other $t \mathrm{~s}<0.82$, all $p \mathrm{~s}>$ .20 . (This failure to choose relationally was not due to lack of understanding of the task, as most of the 4-year-olds chose the similar item on all four filler triads.) In contrast, the 6- and 8-year-olds responded reliably above chance in all conditions, all $t \mathrm{~s}>3.92$, all $p$ s $<.01$ (see Table 1).

Further analyses including the factors of higher-order relation (symmetry or monotonicity) and dimension of standard (size or saturation) revealed a significant interaction between the dimension of the standard and age, $F(2,69)=3.09, p=.05$. Bonferroni comparisons using a family alpha of $p<.01$ revealed that the 6-year-olds performed

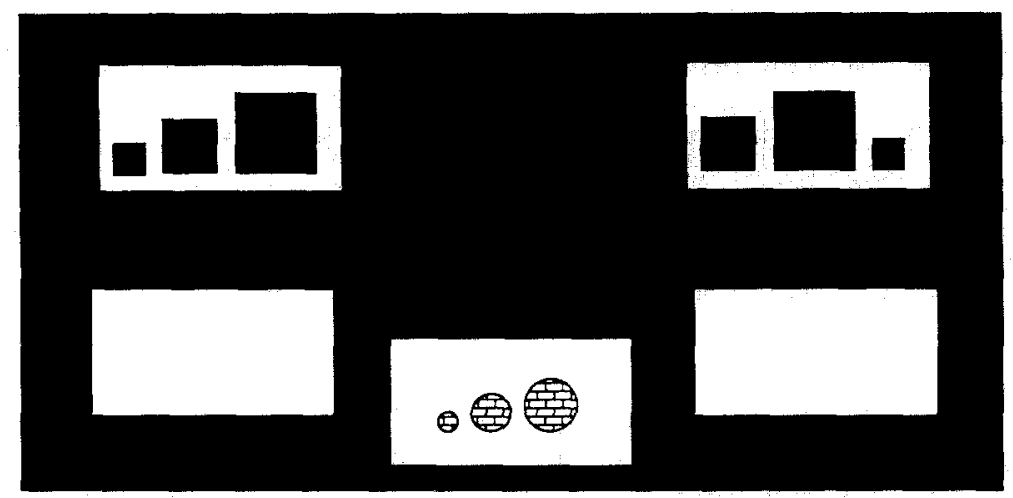

Frg. 2.-Stimulus presentation 
TABLE 1

Mean Proportion of Relational Responses by Age and CONDITION IN EXPERIMENT 1

\begin{tabular}{ccc}
\hline Age & Same-Polarity & Opposite-polarity \\
\hline 4-year-olds: & & \\
Same-dimension ....... & .68 & .49 \\
Cross-dimension ...... & .49 & .48 \\
6-year-olds: & & .77 \\
Same-dimension ....... & .90 & .72 \\
Cross-dimension ...... & .75 & .93 \\
8-year-olds: & & .80 \\
Same-dimension ....... & .96 & .90 \\
Cross-dimension ...... & & \\
\hline
\end{tabular}

more relationally when the standard depicted a change in saturation $(M=81 \%)$ than when the standard depicted a change in size $(M=76 \%)$. The opposite pattern was obtained with the 8-year-olds (saturation, $M=86 \%$; size, $M=93 \%$ ). There was no difference in the 4-year-olds responses to saturation $(M=53 \%)$ versus size $(M=$ $54 \%$ ). No other main effects or interactions were significant.

\section{Discussion}

The data from the triads task are consistent with the relational shift hypothesis: (a) at all ages, children were better able to recognize higher-order commonalities when they were supported by lower-order commonalities, and $(b)$ only the older children (6- and 8-year-olds) were able to recognize higher-order commonalities in the absence of supporting lower-order commonalities. Four-year-olds required lower-order relational support to see the match.

Children's active processing of the similarity matches was revealed in their spontaneous comments during the task. Even on the Same-dimensional triads, 6-year-olds sometimes articulated their choices, as in these remarks on symmetry: "Big little big, that's the pattern." and "I figured it out, this is one different color in the middle." On Cross-dimensional matches, children some-

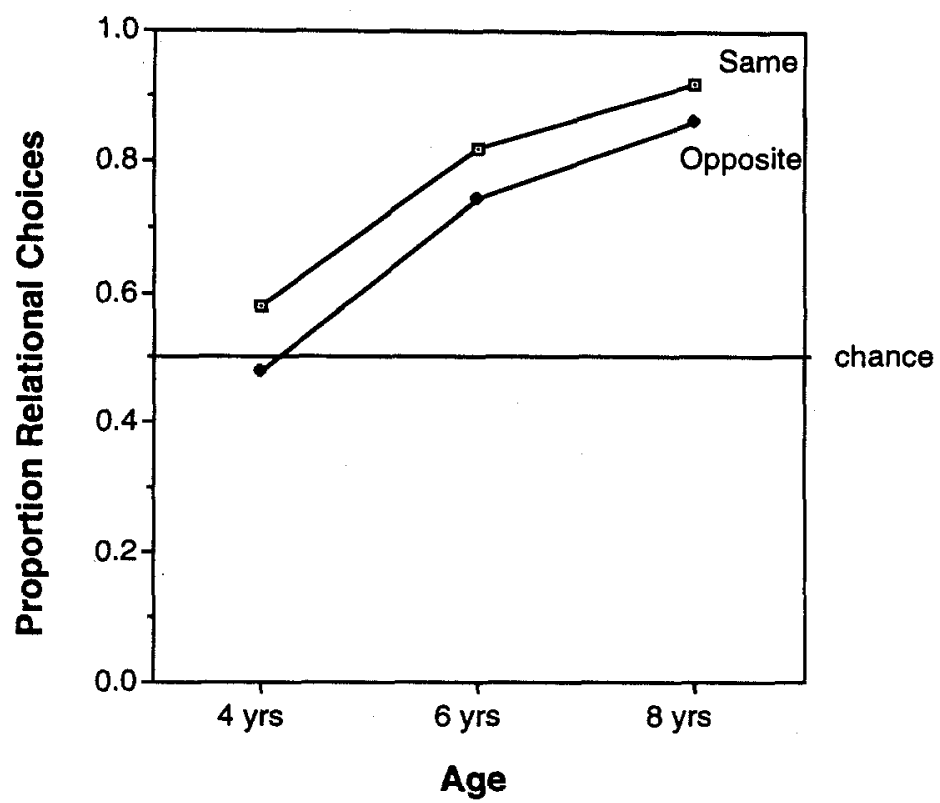

Fig. 3.-Performance of children in Experiment 1 on Same- and Opposite-polarity trials 


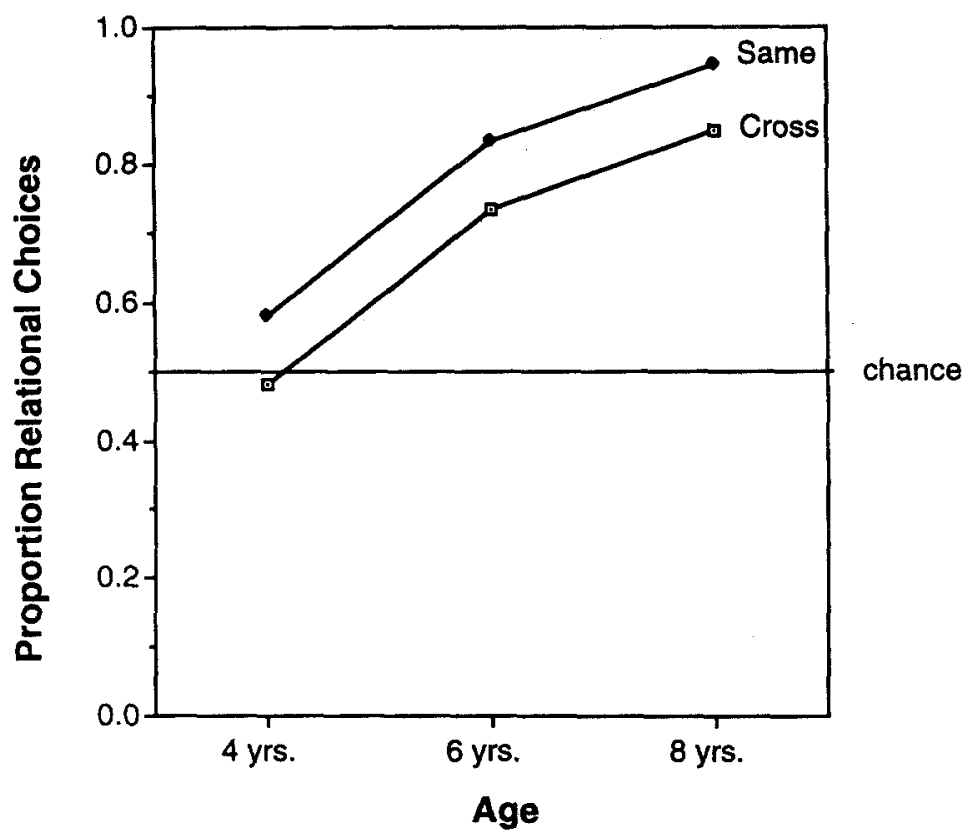

Fig. 4.-Performance of children in Experiment 1 on Same- and Cross-dimension trials

times named the correspondences, as in this 6-year-old's comment on symmetry: "This is a big one, this is pink. This is a small one, this is red." Another strategy was to map across a relational system from a more familiar domain: "A dark one and a big one make daddies. The other one [the rejected alternative] has two twins and a daddy on the side" (see Gentner \& Rattermann, 1991). The emerging appreciation of relational commonality can be seen in this comment by an 8-year-old, who after struggling with her first several Cross-dimension matches, then excitedly articulated a startlingly apt description of relational similarity: "It's exactly the same, but different!" She proceeded to choose relationally for all the remaining triads.

These results extend and refine the findings on the relational shift. It appears that the perception of pure higher-order relational commonality indeed emerges later than the perception of matches supported by both higher-order and lower-order relations. With this foundation, we now move to our second goal, namely, to determine whether this gain in relational sensitivity is due to changes in knowledge representation (Brown, 1989; Gentner \& Rattermann, 1991; Vosniadou, 1989) or to changes in general processing ability (Case, 1987; Halford, 1987, 1993). In the remainder of this article, we test the core prediction of the knowledge-change hypothesis: that providing children with insight into the domain relations should increase their ability to perceive higher-order similarity. This experience could take the form of direct instruction in relational categories (as investigated in Experiment 3), but we also wished to explore the possibility of experiential learning of domain relations. Specifically, we wished to investigate a particular experiential learning mechanism, that of progressive alignment. According to this hypothesis, repeated comparisons involving overall concrete similarity can facilitate noticing higher-order relational commonalities, and thus promote the subsequent recognition of pure higher-order relational similarity.

The first assumption of the Progressive Alignment hypothesis is that the similarity comparison process is one of alignment and mapping between representational structures, as in the structure-mapping process for analogy (Gentner, 1983, 1989). We further assume that structural alignment is easier the more commonalities are present, provided that they form a structurally consistent system (Gentner, 1989; Gentner, Rattermann, \& Forbus, 1993; Gentner \& Toupin, 1986; Goldstone \& Medin, 1994; Markman \& Gentner, 1993). Further, we assume that one result of carrying out a similarity com- 
parison is to highlight the relational structure, making it more salient (Forbus \& Gentner, 1986; Gentner \& Wolff, in press). A second innovative aspect of the Progressive Alignment hypothesis is the assumption that the process of carrying out a similarity comparison may lead to a change in the representation, and that this change will tend to increase the uniformity of the two representations (Gentner et al., in press; Gentner \& Markman, 1995; Gentner \& Rattermann, 1991; Gentner \& Wolff, in press). Thus the process of comparison and alignment acts both to make relational commonalities more salient and to make the representations slightly more uniform. Thus, experience comparing literally similar pairs that share a given higher-order relation (e.g., symmetry) promotes the ability to recognize this higher-order commonality in more abstract (e.g., cross-dimensional) comparisons. This claim that experience with concrete similarity promotes the development of abstract similarity differs sharply from the standard view of category learning, dating back to behaviorist research, which assumes that the learning process ends when learners find categories that are sufficiently abstract to subsume the training stimuli.

Some aspects of this proposal are already well attested. Many researchers have suggested that one result of a comparison is to highlight common elements and thus promote common abstractions (Brown et al., 1986; Elio \& Anderson, 1981; Forbus \& Gentner, 1986; Gick \& Holyoak, 1980, 1983; Hayes-Roth \& McDermott, 1978; Medin \& Ross, 1989; Ross, 1989; Thorndike, 1903). For example, when Gick and Holyoak (1983) asked participants to write out the commonalities between two analogous passages, the common schema became more accessible in a subsequent memory task. However, the extant psychological research has concentrated chiefly on directed schema extraction from explicit comparisons. Our proposal goes further in suggesting that the mere process of carrying out a similarity comparison, even without explicating the resulting common frame, can increase the salience of the common structure. For example, Markman and Gentner (1993) gave adult participants a difficult mapping task in which there were competing mappings between two scenes. Participants were more likely to choose a structurally consistent relational mapping over a competing mapping that was based on a superficial but striking object match if they had previously rated the similarity of the two scenes. This is evidence that the process of carrying out a similarity comparison involves an alignment of relational structure. Our goal in this research was to test the strong claim that experience with concrete similarity promotes recognition of abstract relational similarity.

A follow-up study to Experiment 1 provided some encouragement for this possibility. We asked whether children would show positive transfer effects if they experienced concrete similarity comparisons followed by abstract relational similarity (when both involve the same relational structure). To test this, we brought back (within 1 week, mean delay $=2$ days) the children who had participated in Experiment 1 and gave them the task again, but in the alternate polarity condition. Thus, one-half of the children were presented with the more abstract Oppositepolarity triads after experiencing the more concrete Same-polarity triads. The prediction was that these children would perform more relationally on the Opposite-polarity triads than those who had received the Opposite-polarity triads wth no prior concrete experience.

We focused on the 4-year-olds, who in Experiment 1 had shown no ability to recognize abstract higher-order relational similarity in the absence of supporting lowerorder relational similarity. In the follow-up experiment, on the Same-dimension trials the 4-year-olds showed the predicted improvement: $M=49 \%$ for Opposite-polarityfirst and $M=60 \%$ for Opposite-polaritysecond, $t(22)=1.84, p<.05$, one-tailed. This did not appear to be a general practice effect in that there was no such improvement on the Same-polarity trials: $M=68 \%$ for Same-polarity-first and $M=53 \%$ for Same-polarity-second. This pattern is consistent with the possibility that preschoolers' ability to extract pure higher-order relational similarity was improved by prior experience with similarity matches in which the same higher-order commonality was supported by concrete lower-order commonalities. Although the improvement was slight, it occurred without feedback and with a relatively small number of concrete trials presented some days before the abstract trials.

Our goal in Experiment 2 was to test the Progressive Alignment hypothesis more systematically. We focused on 4-year-olds, since they seemed to show little or no initial 


\section{Child Development}

recognition of pure higher-order relations. We reasoned that if experience with concrete similarity promotes recognition of abstract relational similarity, then experience with Same-dimensional triads should facilitate performance on Cross-dimensional triads. To test this prediction, we gave children the same triads as in Experiment 1, but blocked them so that the eight Samedimension triads preceded the eight Crossdimension triads, instead of mixing the triads as in Experiment 1. According to the Progressive Alignment hypothesis, this should lead to improved performance on the Cross-dimensional triads. However, a further control is necessary here, for there is a possible alternate explanation of the predicted result (of improved performance on the abstract triads). Such an improvement could simply come about through some general benefit of practice on easy triads, rather than specifically through the alignment and highlighting of common relational structure.

To rule out this explanation, a control group was run. Like the experimental group, the control group received eight Samedimension triads followed by eight Crossdimension triads. However, the make-up of the Same-dimension triads was varied between the groups. Whereas the experimental group received four size-change and four saturation-change triads, the control group received eight size-change triads. Thus the control group should experience any benefits deriving from easy practice triads, but only the experimental group is given the opportunity to align concrete similarity matches along both dimensions. If, as claimed by the Progressive Alignment hypothesis, alignment of concrete matches helps highlight relational structure and paves the way for abstract matches, then the experimental group should outperform the control group (as well as the children in Experiment 1) on the Cross-dimension triads. More specifically, we predicted that those 4-year-olds who successfully align the rela- tional structures in a block of Samedimension trials involving size and a block of Same-dimension trials involving saturation should be best able to respond to the relational similarity on a subsequent block of Cross-dimension trials. Thus, we predicted a positive relation between performance on Same-dimension trials and performance on Cross-dimension trials in the experimental condition of Experiment 2 and no such relation in the control condition or in Experiment 1.

\section{Experiment 2}

\section{METHoD}

\section{Participants}

The participants were 24 4-year-olds, 13 boys and 11 girls, mean age 4-6 (range $=4-2$ to 5-0). Six boys and six girls were assigned to the experimental condition (mean age 4-6, range $=4-2$ to 4-9) and seven boys and five girls were assigned to the control condition (mean age 4-6, range $=4-2$ to 5-0). Participants in this and the remaining experiments were recruited from the Champaign-Urbana community and tested individually in a laboratory at the Beckman Institute at the University of Illinois.

\section{Materials}

The stimuli in the experimental condition were the Same-polarity stimuli from Experiment $1:^{3}$ eight Same-dimension triads, eight Cross-dimension triads, and six training and filler triads. The stimuli in the control condition were the same as those used in the experimental condition, except that in the Same-dimension trial block, instead of four Same-dimension size triads and four Same-dimension saturation triads, children received eight Same-dimension size triads. The new size triads were created by reversing the polarity in the original Samedimension size triads. ${ }^{4}$

\section{Procedure}

The procedure was identical to that of Experiment 1, except that in the experimen-

${ }^{3}$ The dimension manipulation has certain advantages over the polarity manipulation. In the monotonicity triads, the same and different polarities are mirror images (e.g., 1-2-3, 3-2-1), so a child could conceivably follow a rule such as "read both directions when looking for a match." This is not the case for dimension. There is no simple transformation between size and color, so in order to perform relationally on the Cross-dimension match the child must rely on abstract relational structure. The remaining experiments all utilize dimension as the varying aspect, holding to Same-polarity.

${ }^{4}$ Polarity was not manipulated as an experimental factor. All of the triads in the experiment were Same-polarity. That is, the polarity was the same in the standard and the relational choice. However, children received monotonicity from left to right in some triads and monotonicity from right to left in others. 
tal condition the triads were presented in the fixed order shown in Table 2, and in the size-only control condition the triads were presented in the same fixed order except that the Same-dimension-color triads were replaced with Same-dimension-size triads. These fixed orders were created by first blocking by dimension so that the Samedimension trials came before the Crossdimension trials and then choosing an order that seemed to facilitate alignment of structure. The idea was to maintain the same higher-order relational match between successive trials, along with other commonalities where possible. For example, a sample Same-dimension sequence might be symmetry in size, then symmetry in color, then monotonicity in color, then monotonicity in size, and so on. The Cross-dimension triads were also sequenced by higher-order relations. As in Experiment 1, no feedback was given in either condition.

\section{Results}

As predicted, children in the experimental condition who performed well on the Same-dimension trials also performed well on the Cross-dimension trials. The children who scored above the median score $(62 \%$, range $=38 \%-100 \%)$ on the Samedimension trials responded relationally to $80 \%$ of the Cross-dimension trials, as compared to $46 \%$ for the children who scored at or below the median on the Same-dimension trials.

A chi-square analysis using a median split on both the Same-dimension and the Cross-dimension $(\mathrm{Mdn}=62 \%$, range $=$ $25 \%-88 \%$ ) trials supported the association between these two variables, $\chi^{2}(1)=12.03$, $p<.005$. As Table 3 shows, the relation is
TABLE 3

Number of Children Performing Above and Below the Medians on the Same-Dimension and Cross-Dimension Trials in EXPERIMENTS 2 AND 1

\begin{tabular}{|c|c|c|}
\hline \multirow[b]{2}{*}{ SAME-DIMENSION } & \multicolumn{2}{|c|}{ Cross-Dimension } \\
\hline & Below & Above \\
\hline \multicolumn{3}{|l|}{ Experiment 2: } \\
\hline \multicolumn{3}{|l|}{ Experimental condition: } \\
\hline 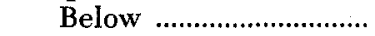 & 7 & 0 \\
\hline 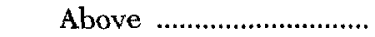 & 0 & 5 \\
\hline \multicolumn{3}{|l|}{ Control condition: } \\
\hline 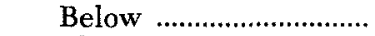 & 2 & 3 \\
\hline Above & 3 & 4 \\
\hline \multicolumn{3}{|l|}{ Experiment 1: } \\
\hline 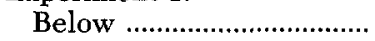 & 5 & 1 \\
\hline 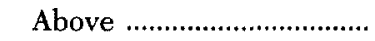 & 4 & 2 \\
\hline
\end{tabular}

quite strong. All 12 of the children in the experimental condition fell into the two predicted cells (above-above and below-below). That is, children who were above the median on the Same-dimension triads were above the median on Cross-dimension triads, and those below the median on Samedimension triads were below the median on Cross-dimension triads.

In contrast to the experimental condition, the size-only control condition showed no reliable relation between performance on the Same- and Cross-dimension trials, $x^{2}(1)$ $=0.01, p>.50$ (see Table 3). Children who scored above the median on the Samedimension trials $(\mathrm{Mdn}=100 \%$, range $=$ $25 \%-100 \%$ ) responded relationally to $52 \%$ of the Cross-dimension trials, as compared to $50 \%$ relational responding for children who scored at or below the median. Thus it

TABLE 2

Order of Triads in THE Expermental Condition OF EXPERIMENT 2

\begin{tabular}{lll}
\hline Dimension & $\begin{array}{l}\text { Dimension } \\
\text { of Standard }\end{array}$ & \multicolumn{1}{c}{$\begin{array}{c}\text { High-Order } \\
\text { Relation }\end{array}$} \\
\hline same & size & monotonic-increase \\
same & size & symmetry \\
same & color & symmetry \\
same & color & monotonic-increase \\
cross & size & symmetry \\
cross & color & monotonic-increase \\
cross & size & monotonic-increase \\
cross & color & \\
\hline
\end{tabular}

NoTE. - The children received two of each of the eight triad types. 


\section{Child Development}

does not appear that the improvement in the experimental group is due simply to practice with easy triads.

A further test of the Progressive Alignment predictions is to compare the experimental group, which received the eight concrete Same-dimensional matches before the eight Cross-dimensional matches, with the subjects in Experiment 1, who received the same 16 triads in mixed order. An analysis of the results of Experiment 1 revealed that performance on the Same-dimension trials did not predict performance on the Crossdimension trials. The children who scored above the median $(62 \%$, range $=38 \%-88 \%)$ on the Same-dimension trials responded relationally to only $48 \%$ of the Crossdimension trials. This was no better than the $50 \%$ relational responses on Crossdimensional trials produced by the children who scored at or below the median on the Same-dimension trials (see Table 3 ). A chisquare analysis failed to indicate any relation between Same-dimension and Crossdimension performance, $\chi^{2}(1)=0.44, p>$ .15 .

To compare all three of these groups, we performed a $3 \times 2$ ANOVA including condition (experimental, control, or Experiment 1) and Same-dimension-performance (above or below median) as betweensubjects factors, and percentage correct on the Cross-dimension trials as the dependent variable. The analysis revealed reliable main effects of both condition, $F(2,30)=$ $3.34, p<.05$, and Same-dimension-performance, $F(1,30)=5.17, p<.04$, and a reliable interaction between condition and Same-dimension-performance, $F(2,30)=$ $5.35, p<.02$. Inspection of the means (reported again here for convenience) revealed a marked contrast. The children in the experimental condition in Experiment 2 who performed above the median on the Samedimension trials responded most relationally to the Cross-dimension trials $(M=80 \%)$. The other five groups showed uniformly low relational responding on the Crossdimension trials ( $M \mathrm{~s}$ ranged from $46 \%$ to $52 \%$ ). Three pairwise Bonferroni contrasts compared the above- and below-median groups in each condition. As predicted, only in the experimental condition in Experiment 2, where Same- and Cross-dimension were blocked and both size and saturation trials were presented in the Same-dimension block, did Same-dimension performance predict Cross-dimension performance. A final contrast found a reliable difference be- tween the above-median group in the experimental condition in Experiment 2 and the other five groups. The family alpha for the contrasts was $p<.01$.

\section{Discussion}

The results of the experimental condition in Experiment 2 are consistent with the claim that repeated experience with concrete triads led to an increase in the children's ability to recognize higher-order relational similarity. This pattern of results is not likely to have been produced by simple task practice effects, as discussed above. It also seems unlikely that the pattern could have resulted from individual differences. If the association between Same-dimension and Cross-dimension trials in the experimental condition were due to the fact that certain talented children simply performed well across the board (perhaps because they entered the task already attuned to relational similarity), then we should have been such an association in the control condition and in Experiment 1, but as described above, this was not the case: In neither case did performance on concrete trials predict performance on abstract trials. A further argument against the individual differences explanation comes from examining performance on the Same-dimension trials. The median score for the experimental condition of Experiment 2 was no higher than that for Experiment 1 (62\% in both), and was considerably lower than that for the sizeonly control condition (100\%). Thus, it is not the case that the children in the experimental condition were simply "smarter" from the start. Individual differences do not appear to account for the pattern of results.

Together these results suggest that only the children who successfully aligned and extracted the relational structure of both dimensions prior to the Cross-dimension trials were able to perform relationally on these trials. Children who received Same- and Cross-dimension trials mixed together, or received only size/size trials prior to the Cross-dimension trials, were unable to recognize the higher-order match on the Crossdimension trials. The results are not consistent with explanations based on individual differences and/or practice effects. Although the number of participants in this experiment was not large $(N=24)$, the pattern of results is intriguing. It suggests that the process of carrying out concrete similarity comparisons on both dimensions-the process of aligning, highlighting, and re-repre- 
senting the relational structure-produced a felicitous condition for the experiential detection of higher-order commonalities.

A key claim of the knowledge-change view is that learning about domain relations facilitates the recognition of relational similarity. If this is true, then we should still see this facilitation if children are taught the domain relations by another means. One particularly interesting route is the use of relational language. We conjected that providing labels for the higher-order relations might increase the salience of the common relational structure of the stimuli. Giving children labels has proven effective in improving performance of children in a variety of tasks. There is a vast amount of research demonstrating that noun labels can call attention to object categories, overriding competing associations (e.g., Gelman \& Markman, 1987; Markman, 1989; Markman \& Hutchinson, 1984; Waxman \& Gelman, 1986; Waxman \& Hall, 1993; Waxman \& Markow, 1995). Gentner (1982, in press) has speculated that such effects may be stronger for relational terms than for nominal terms. There is evidence that naming relational categories can make them more salient. For example, Rattermann and Gentner (1996) have shown that labeling three objects of increasing size "baby," "mommy," and "daddy" improves children's performance in an analogical mapping task where the relation they must attend to is "monotonic increase" (see Gentner \& Rattermann, 1991; Gentner et al., 1995; Rattermann \& Gentner, 1996).

In Experiment 3, we investigated whether learning labels for higher-order relational categories would improve children's ability to perceive relational similarity. We taught a group of 4-year-olds to label and categorize the higher-order relations of symmetry and monotonicity and then tested them in the triads task. To maximize the chance of children learning the correct mapping of the relational label, we used a rich training technique. First, we introduced the children to a "picky penguin" (Waxman \& Gelman, 1986) and labeled the relational structure. For example, for symmetry we said, "This is a very picky penguin and he only likes things that are even." We then presented the children with figures that were either symmetrical or nonsymmetrical (e.g., the relational and the nonrelational choices from Experiment 1; see Fig. 1). We asked the children what the picture was called (labeling) and whether the penguin that only likes even things would like the picture (categorization). Then we gave the children feedback as to whether they had categorized correctly. If the children were correct we continued with the next trial. If they were wrong we gave them an explanation (e.g., we pointed out the symmetrical pattern and explained why the figure was even).

Because we wanted to separate the possible benefits of gaining relational knowledge from those of comparison and alignment, one training technique we did not utilize was to invite comparison of the figures; instead we presented the items one at a time. After this training, children were presented with the eight Cross-dimension triads from Experiment 2. The question was whether training on the higher-order relations would lead to increased relational performance on the Cross-dimension comparisons. The plan was to compare performance on the categorizing and labeling training to performance on the Cross-dimension triads task.

\section{Experiment 3}

\section{Method}

\section{Participants and Materials}

The participants were 12 4-year-olds, six boys and six girls (mean age 4-6, range = 4-1 to 5-0). The stimuli were the 16 triads used in Experiment 2. Each figure from the eight Same-dimension triads was presented one at a time, creating 24 training items, 12 for symmetry and 12 for monotonicity. Because the stimuli were formed from the triads, each of the two sets of 12 contained eight examples of the higher-order relation (e.g., $\mathrm{xXx}$ ) and four distractor patterns (e.g., $\mathrm{xxX}$ ). We also used a toy penguin and walrus and two plastic baskets as part of the training task.

\section{Procedure}

Training: Labeling and categorizing. - The child was seated at a table in front of the toy penguin and the two baskets, one near the penguin and one on the other side of the table. The experimenter told the child that the penguin was very picky and only liked things that were "even." The child was told to put the even things in the picky penguin's basket and the things that were not even in the other basket. Then children were given the 12 symmetry training cards one at a time and asked, "Do you know 


\section{Child Development}

what this is?" The experimenter reminded the child that the picky penguin only liked things that were even and asked whether the picky penguin would like the card on the table. The child then put the card in one of the baskets. If the choice was correct, the experimenter said, "That's right, that one was even"; if incorrect, the experimenter retrieved the card and explained in detail why the answer was wrong (e.g., "No, that one is not even. See, that one has two little ones together and to be even, it would have to have two the same on the outside and a different one in the middle. In this one, the different one is on the side. This is something else, so let's put it in the other basket").

This procedure was repeated for each of the figures from the Same-dimension-symmetry triads. Then the penguin was taken away and the child was introduced to a picky walrus who only liked things that were "more and more." The same procedure was then repeated for the 12 monotonicity cards, using the label "more and more."

Test: Cross-dimension triads.-After the categorization training, the child was told that it was time to play a different game. The triads task was conducted in the same manner as in Experiment 1. After the two training triads and one filler triad, the child received the eight Cross-dimension triads with one filler triad after the first four triads. The triads were presented in a fixed order designed to facilitate transfer as determined by pilot testing: first, the four symmetry triads and then the four monotonicity triads (see the cross-dimension portion of Table 2 for exact order of presentation). As before, no feedback was given.

\section{RESULTS}

\section{Categorization Task}

As predicted, children who did well on the categorization task tended to do well on the Cross-dimension triads task. Children who scored above the median $(67 \%$, range $=42 \%-81 \%$ ) on the categorization task responded relationally to $67 \%$ of the Crossdimension trials, whereas children who scored at or below the median on the categorization task responded relationally to $52 \%$ of the Cross-dimension trials (chance = 50\%). As in Experiment 2, a median-split analysis was performed. Ten of the 12 children fell into the predicted cells (belowbelow and above-above, see Table 4). A chi-square analysis confirmed the noninde-
TABLE 4

Number of Children Performing Above and BeLOW the Medians of the Categorization TASK aNd the Triad TaSk In EXPERIMeNT 3

\begin{tabular}{|c|c|c|}
\hline \multirow[b]{2}{*}{ Categorization TASK } & \multicolumn{2}{|c|}{ Triad Task } \\
\hline & Below & Above \\
\hline 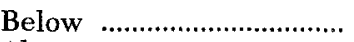 & 6 & 0 \\
\hline Above & 2 & 4 \\
\hline
\end{tabular}

pendence of performance on these two tasks, $\chi^{2}(1)=6.00, p<.025$.

\section{Production of Labels}

Overall, there were very few productions of the labels. Of the 12 children in the experiment, five did not correctly label any of the 24 items, four produced two or three correct labels, and only three children produced more than eight correct labels. Although this limited amount of production data does not permit firm conclusions, there was an interesting qualitative relation between propensity to label and performance on the Cross-dimension triads task. The mean proportions correct were $55 \%, 56 \%$, and $71 \%$ for the children producing $0,2-3$, and 8 or more labels, respectively.

\section{Discussion}

Learning to label and categorize higherorder relations enhanced 4-year-olds' recognition of those higher-order commonalities. Again, the number of participants was small $(N=12)$, and the gain in Cross-dimensional performance was not large, but in view of the relatively modest amount of experience the children had with the relational labels, the results are encouraging. These results buttress the knowledge-based account of the relational shift and the claim that children's increasing ability to notice relational similarity is due at least in part to their learning of higher-level relational categories. These results also raise the intriguing possibility that language learning-specifically, learning the names of relational categories-may be a factor in the development of relational similarity (see Gentner \& Rattermann, 1991).

\section{Experiment 4}

In Experiment 4, we returned to the Progressive Alignment hypothesis with the intent of creating a more definitive test. We showed in Experiment 2 that a relatively modest amount of experience with Same- 
dimensional comparisons can facilitate children's performance on Cross-dimensional similarity. However, these benefits were limited to those children who did well on the Same-dimension trials, raising the concern that the apparent training effects might result from certain children being advanced on both tasks. Against this possibility is the fact that, as discussed above, this positive relation between performance on the Samedimension and Cross-dimension tasks was found only when the former preceded the latter (in Experiment 2), and not when the two kinds of trials were mixed together (in Experiment 1). However, a more convincing demonstration of the hypothesis would be to show that, across the board, giving children more insight into the Same-dimension task will improve their performance on the Cross-dimensional task. Therefore, in Experiment 4 we trained children to a criterion on the Same-dimension triads and used a pretest-posttest comparison to see if this training led to the predicted gain in Crossdimension performance.

A second goal of Experiment 4 was to check for a possible problem with the stimuli in the prior studies. The children's task was to choose whether the relational choice or the nonrelational choice was a better match for the standard. However, because the matching relational items were always examples of either symmetry or monotonicity, children might simply have learned to choose the "good" pattern (either symmetry or monotonicity) over the other alternative (the nonrelational choice, which was always a permuted pattern of the same component objects). It is even conceivable that children sometimes remembered and chose the same items on the Cross-dimension task as they had chosen on the Same-dimension task. That is, children might simply be learning to select certain response alternatives or classes of alternatives (the "good" relations), rather than carrying out a cross-dimensional comparison with the standard. In either case, children's responding would have mimicked successful Cross-dimensional comparison without such comparisons actually occurring.

To eliminate these possibilities, in Experiment 4 , the response alternatives for the Cross-dimension triads were altered. Instead of choosing between a relational alternative and a nonrelational alternative, children were given a monotonicity alternative and a symmetry alternative. Thus they had to choose between two good relational alternatives, only one of which matched the standard (see Fig. 5). Since children had experienced both these patterns as the best match equally often in the Same-dimension training, the strategy of picking a known pattern would not work. There was no way to choose the correct relational pattern without comparing the alternatives to the standard.

To establish a baseline, we first gave the 4-year-olds a pretest using the new kind of Cross-dimension triads. This was followed by a training procedure on the Samedimension triads in both dimensions, after which we again tested children on the new Cross-dimension triads. In the Samedimension training, we were careful to use only terms specific to the particular dimen-

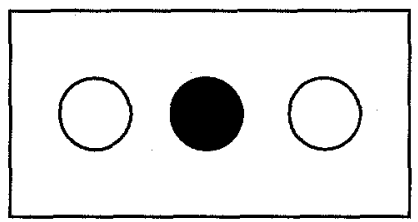

Standard



Matching Relational Choice

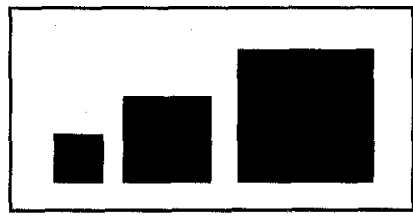

Non-matching Relational Choice

FIG. 5.-Sample of Cross-dimension triads used in Experiment 4 


\section{Child Development}

sion. We know from Experiment 3 that Cross-dimensional performance can be facilitated by giving children common abstract labels (such as "even" or "more and more") that invite them to perceive the crossdimensional relational abstraction. Here we are interested in a pure test of the Progressive Alignment hypothesis that experience aligning within dimensions promotes alignment of the same relational structure across dimensions. We therefore avoided giving children domain-general abstractions in order to see whether they could arrive at the abstraction for themselves. Thus, the experimenter took care to use dimension-specific terms such as "darker" or "bigger" rather than terms that could apply to both size and saturation, such as "more" for monotonicity. The hypothesis was that insight into the Same-dimension triads would make children better able to recognize the pure higher-order commonalities in the Crossdimension triads.

\section{METHOD}

\section{Participants}

The participants were 11 4-year-olds, five boys and six girls (mean age 4-6, range $=4-0$ to $5-0$ ). Three additional children were tested and replaced. One child was eliminated due to failure to meet criterion (see Training), one due to experimenter error, and one due to poor performance on the filler trials (more than one incorrect).

\section{Design and Materials}

The dependent measure was posttest Cross-dimension performance compared to pretest Cross-dimension performance. The eight Same-dimension triads were the same as those used in Experiments 1 and 2. The eight Cross-dimension triads were like those used in Experiments 1 and 2 except that the nonrelational choice was replaced by a nonmatching relational choice (see Fig. 5). This new figure depicted either symmetry or monotonicity (whichever was not depicted in the standard and the matching relational choice). In order to control object-level similarity, the foil (i.e., the nonmatching relational choice) utilized the same objects as the matching relational choice, insofar as possible. For example, if the matching relational choice was a symmetrical pattern of blue circles (light dark light), the foil was a monotonically increasing pattern of blue circles (light medium dark). The training and filler triads were identical to those used in the previous experiments, except that two filler triads were added.

\section{Procedure}

Pretest.-Children were given two training trials, a filler trial, and then four Cross-dimension trials with a filler trial between the first and last two. There was no feedback.

Training.-After the pretest, children were trained to a criterion on the eight Same-dimension triads. After each trial the child was given feedback and a "samedimension explanation" if needed. If the child chose the relational choice, the experimenter said, "That's right! Let's try another one." If the child chose the nonrelational choice, the experimenter said, "That is not quite right. I think it would go better here. Let me show you how to figure it out." Then the experimenter would explain the correct choice using terms specific to the dimension that was involved in the comparison (size or color saturation). The experimenter used dimension-specific terms such as "dark" or "bigger" and avoided domain-general terms that apply to both size and saturation, such as "more" for monotonicity or "even" for symmetry. For example, in a samedimension explanation, the Experimenter might point to a symmetrical standard and say, "See, this one has two little ones on the sides and a big one in the middle. And see [pointing to the relational choice], this one has two little ones on the sides and a big one in the middle. That is why this one goes with this one. This one [pointing to the nonrelational choice] is not right because it has two little ones here and a big one on the side. Let's try another one!"

The criterion for the training trials was seven out of the eight Same-dimension trials correct. If a child got more than one trial wrong, the entire set of eight trials was repeated. This was continued until the child met the criterion (nine children) or until the experimenter judged the child to be getting frustrated with the task. In this case, the experimenter repeated only the incorrect triads until the child got them all correct. Three children fell into this category. Finally, one child was unable to meet this criterion and was dropped from the analyses. The 11 children included in the analyses reached the criterion in an average of $\mathbf{1 5 . 4}$ training trials (range $=8-24$ trials).

Test.-After completing the training task, the children were presented with the eight Cross-dimension triads. All of these triads had two "good" relational choices. Four of these triads were identical to the Crossdimension triads in the Pretest and four 
were new. The triads were presented in the same manner as in previous experiments. No feedback was given.

\section{Results AND Discussion}

\section{Pretest}

The first question was how the children would initially perform on the new kind of Cross-dimension trial (with two "good" relation choices). As in the prior studies, the 4year-olds initially showed no ability to choose the matching higher-order pattern. They chose the matching relational response on $41 \%$ of the Cross-dimension trials: chance $=50 \% ; t(10)=1.07, p>.15$, onetailed.

\section{Test}

As predicted, relational selectivity was elevated on the Cross-dimension trials following the Same-dimension training trials. Ten of the 11 children performed more relationally in the posttest than in the pretest. Overall, the children chose the matching relational response on a mean of $74 \%$ of the Cross-dimension trials. This was reliably above the pretest performance, $t(10)=5.39$, $p<.0005$, one-tailed, and also reliably above chance, $t(10)=4.01, p<.003$, onetailed. Consistent with the Progressive Alignment hypothesis, learning to align the Same-dimension triads improved children's recognition of the higher-order relational commonality in the Cross-dimension trials.

\section{General Discussion}

The present research suggests four conclusions. First, there is support for the claim of a relational shift from early reliance on concrete similarity to later ability to perceive purely relational commonalities. Second, our findings support the claim that this development is driven by changes in domain knowledge, rather than changes in global competence or processing capacity. Third, we found evidence that language learning-specifically, the acquisition of relational terms - can promote the development of relational comparisons. Finally, we found evidence that the process of similarity comparison itself is instrumental in this development. Although the number of participants in each of the experiments was not large, the consistency in the overall pattern of the results across the four experiments provides converging support for these conclusions. Based on these results, we conjecture that the acquisition of relational language and the process of relational comparison provide mutual bootstrapping that drives representational change.

\section{Knowledge and the Relational Shift}

According to the "career of similarity" framework put forward by Gentner and Rattermann (1991), children's very early similarity matches rely on massive overlap between the items; with experience they become able to appreciate partial similarity, with object matches preceding relational matches and in turn higher-order relational matches (see also Gentner \& Medina, 1996). Our current findings support this account of the relational shift. For example, in Experiment 1 , we found that children could recognize relatively concrete similarity involving first-order as well as higher-order matches before they could take advantage of purely higher-order relational commonalities. Recognition of higher-order relational similarity gradually emerged between the ages of 4 and 8 years.

Further, we found that children's performance in the relational task could be improved by their gaining more knowledge of the domain relations. We found that even 4-year-olds, who were unable to recognize pure higher-order matches in Experiment 1, could perceive pure higher-order matches after training in the domain relations (Experiment 3) or repeated experience with the concrete pairs (Experiments 2 and 4). These rapid changes provide strong evidence for a change of knowledge view of the development of relational ability (Brown, 1989; Gentner \& Rattermann, 1991; Goswami, 1992; Vosniadou, 1989), as opposed to maturational changes in global competence (Piaget et al., 1977) or processing capacity (Halford, 1987, 1992).

\section{Progressive Alignment}

According to the Progressive Alignment hypothesis, the process of carrying out a comparison, even a concrete comparison, leads to an alignment of representations (Gentner \& Markman, 1993, in press; Goldstone, 1994; Goldstone \& Medin, 1994; Markman \& Gentner, 1993; Medin, Goldstone, \& Gentner, 1993; Novick, 1988; Ross, 1984, 1989; Schumacher, 1988). Through this alignment the common relational structure becomes more salient. Further, because individuals prefer to see similarity rather than dissimilarity (e.g., Krumhansl, 1978), the process of comparison invites adjustments to promote better alignments, leading to an increase in the uniformity of the representations (Gentner \& Rattermann, 1991; Gentner et al., 1995; Gentner \& Wolff, in press). Progressive alignment acts as a kind of bootstrapping mechanism. As children make similarity comparisons in a domain, 


\section{Child Development}

the representations of the relational structure in the domain become highlighted and possibly more uniform (see below). This in turn makes possible even more abstract, or analogical, comparisons. This cycle can be seen as a kind of disembedding or decontextualizing of relations from initially situated representations to representations that can be matched across domains.

We found three lines of support for the Progressive Alignment hypothesis. First, in Experiment 2, we found that giving 4-yearolds a very small amount of concentrated experience comparing figures that were similar enough for them to align (the four samedimension-size comparisons and the four same-dimension-saturation comparisons) allowed these children to recognize subsequently abstract relational similarity that 4year-olds without the experience could not recognize. This occurred without feedback. Further, the gain could not be attributed to a general practice effect, for no such benefit occurred for children who received eight size-size comparisons. In order for 4-yearolds to recognize abstract higher-order commonalities, general practice in making comparisons was not enough; the results suggest that the relational structure in both of the participating dimensions needed to be aligned and highlighted. Finally, in the follow-up study to Experiment I, we found that this pattern of concrete alignment promoting abstract alignment held for polarity as well as for dimensional alignment. These results support progressive alignment as a mechanism of experiential learning.

There is additional evidence that comparison experiences can lead to recognition of further similarity. Namy, Smith, and Gershkoff-Stowe (in press) found that 2year-olds more readily learned how to categorize two sets of like objects if they were given opportunities to compare the objects. Uttal, Schreiber, and DeLoache (1995) found that 4-year-olds were able to solve a difficult delayed version of the DeLoache (1987) room-to-model mapping task (in which children search for a hidden toy by finding the object in one room that corresponds to a designated object in another, smaller room) if they had first experienced a version in which they were allowed to search immediately. Children in the immediate search task had perhaps achieved an alignment of the two spaces which they could then preserve under more difficult circumstances. In a study by Marzolf and DeLoache (1994), children were better able to make the correspondence between a room and a rather dissimilar model after experience with a room and a highly similar model.

\section{Re-representation}

How might concentrated experience in alignment within each of the two dimensions potentiate subsequent crossdimensional alignment? We conjecture that the relations here are initially represented in a domain-specific manner (e.g., darker than and bigger than). That is, for young children, the representation of a difference in magnitude is bound up with the dimension of difference. Some kind of decomposition is required in order to see these patterns as alike: for example, re-representing the differences in a manner that separates the comparison and the dimension (i.e., greater[darkness $(a)$, darkness $(b)])$. The idea is that such a re-representation makes it easier to notice the commonality between change in size and change in darkness, thus permitting cross-dimensional alignment. This idea is related to work within lexical semantics that seeks lexical entries capturing the entailments of a word (e.g., Lakoff, 1987; McCawley, 1968, 1972; Norman \& Rumelhart, 1975; Schank \& Abelson, 1977).

Our claims about re-representation are related to Karmiloff-Smith's (1991, 1992) theory that representational redescription allows initially implicit procedural knowledge to become available explicitly. However, there are some differences. First, the scale of the changes discussed here is more local than in Karmiloff-Smith's discussion. Whereas Karmiloff-Smith emphasized metalevel insights into one's own processes, we see a role for re-representation even at the simple content level. We suggest also that the accumulation of many small, contentlevel adjustments may potentiate larger insights. Second, our research focuses on mechanisms of re-representation, using computational models from analogy and case-based reasoning (Burstein, 1983; Falkenhainer, 1988, 1990; Falkenhainer, Forbus, \& Gentner, 1989; Forbus \& Oblinger, 1990; Holyoak \& Thagard, 1989; Kass, 1989; Kass \& Leake, 1987; Kolodner \& Simpson, 1989; Novick, 1988; Novick \& Holyoak, 1991; Schank \& Leake, 1989). Third, whereas Karmiloff-Smith proposes that redescription processes begin only after behavioral mastery is attained in a given domain, we assume that alignment and rerepresentation happen from the start. The reason that re-representation does not seem to be occurring in very young children is that their earliest representations are so richly embedded in concrete detail, and so lacking 
in higher-order abstractions, that only the most conservative similarity matches can be made. Hence these early matches and their resulting inferences are often so mundane as to escape adult notice. Nonetheless, we suggest that they pave the way for the more dramatic comparisons to come.

\section{Computational Modeling}

We have hypothesized that an articulation or decomposition of the representation could lead to better recognition of abstract higher-order commonalities. Is this hypothesis reasonable? It is difficult to assess the exact form of a human subject's representation. Moreover, since both representations and processing modes can change over the course of children's development, it is difficult to assign causality. Therefore, we used a computational model to keep the process of comparison fixed while varying the knowledge representation on which it operates. If the postulated changes in knowledge representation produce the observed changes in children's similarity performance, this is evidence that change-ofknowledge could provide a sufficient explanation for the observed effects.

We used the Structure-Mapping Engine (SME) developed by Falkenhainer, Forbus, and Gentner (1986, 1989), a computational model that simulates the similarity comparison process specified by structure-mapping theory (Gentner, 1983). SME is given propositional representations of two situations and produces a favored mapping (a maximal structural alignment). (SME also has inferential and incremental mapping capabilities not germane to the present simulation; see Falkenhainer et al., 1989; Forbus, Gentner, \& Law, 1995.) In the present case, we gave SME representations of the standard and the relational choice in all four of the monotonic-increase triad types (Same-dim/Samepol, Same-dim/Opposite-pol, Cross-dim/ Same-pol, and Cross-dim/Opposite-pol; see Gentner et al., 1995) and it produced mappings indicating its preferred correspondences between the three objects in the standard (e.g., the small, medium, and large squares) and the three objects in the relational choice (e.g., the light, medium, and dark circles).

The critical manipulation was the kind of representations given to SME. We speculated that the younger children represented magnitude difference in a dimensionspecific way (e.g., $A$ is taller than B). In contrast, we assumed that the older children-and the younger children after training-could represent magnitude in a dimension-general manner that separates the specific dimension out of the magnitude comparison (e.g., A's size is greater than $B^{\prime}$ 's size; see Fig. 6). Although the same information is encoded, dimension-general representations more readily permit the recognition of abstract change-of-magnitude (i.e., that one value is somehow "more" than another along their respective dimensions) than do specific dimensional relations like "A is bigger than $B$ " or " $\mathrm{C}$ is darker than D." Such representations should permit the learner to see the common dimensional structure even in the more abstract cases, such as in cross-dimensional pairs.

SME's mappings showed this to be the case. The dimension-general representations received relational mappings for all four pairs. SME aligned the pairs on the basis of common relational structure even when both the dimensions and polarities differed. This parallels the performance of the 8-year-olds in Experiment 1, who were successful at making Cross-dim/Opposite-pol matches. In contrast, when SME was given domain-specific representations, it generally failed to produce a relational alignment. Since the representations did not make manifest the potentially common relational structure across the dimensions, SME was reduced to object matches or to positional alignments. Only in the most concrete case, the Same-dim/Same-pol comparison, did SME align dimensional magnitude relations in its mapping (e.g., TALLER to TALLER). This parallels the performance of the 4-yearolds in Experiment 1, who were at chance in their responding to all but the Same-dim/ Same-pol comparisons.

By their nature, these results cannot serve as proof that these changes occur in children. However, they do constitute an existence proof that change of representation-more specifically, re-representation of dmension-specific magnitude relations as articulated dimension-general magnitude relations-could account for the relational shift in our results. The results of the computational simulation show that rerepresentation can lead to substantial improvement in relational insight while maintaining the same basic comparison process.

One arena in which we speculate that re-representation is important is in dimensional learning. There is evidence that the acquisition of adult dimensional structures 


\section{Child Development}
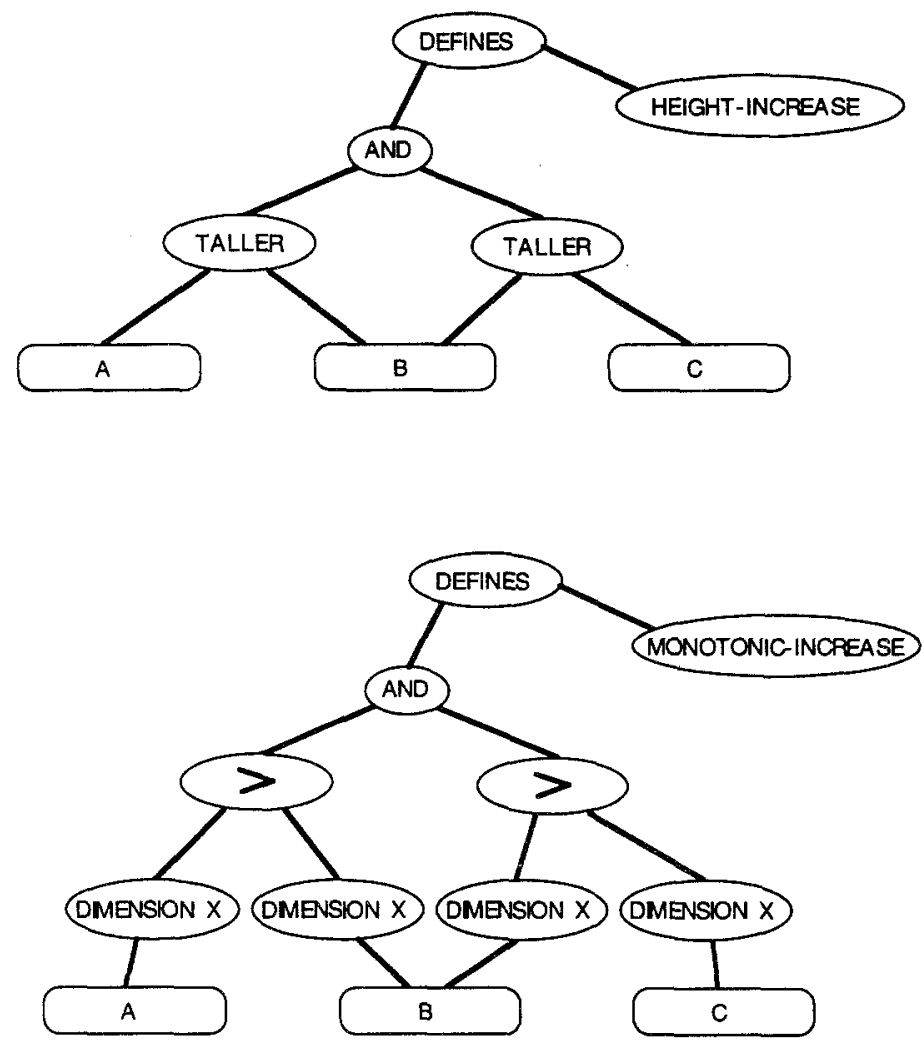

FIG. 6.-The top portion of the figure depicts a dimension-specific representation of height increase in which the dimension of height and the direction of change are embedded. The bottom portion of the figure depicts a dimension-general representation of monotonic increase in which the dimension and the direction of change are disembedded. See text for additional details.

involves a shift from overall global similarity to more differentiated similarity (Foard \& Kemler-Nelson, 1984; Garner, 1978; Shepp, 1978; Smith, 1989; Smith \& Kemler, 1977; Tighe \& Tighe, 1968) characterized by consistent polar alignments across dimensions-for example, loud big, big more (Smith \& Sera, 1992). We conjecture that over development children must not only learn separate perceptual knowledge into dimensions but also come to see them as dimensions, as possessing a coherent (often at least ordinal) structure (see Zwislocki \& Goodman, 1980). Once dimensions are extracted, it becomes possible to grasp structural parallels across different dimensions: for example, cross-domain metaphoric systems such as up/down good/bad and the others discussed by Lakoff and his colleagues (Gibbs \& O’Brien, 1990; Lakoff \& Johnson, 1980; Turner, 1987, 1991).

\section{The Role of Language}

There is a considerable literature showing that labeling sets of objects can facilitate children's forming categories around those objects (e.g., Gelman \& Markman, 1987; Imai \& Gentner, 1993; Markman, 1989; Markman \& Hutchinson, 1984; Waxman, 1991; Waxman \& Gelman, 1986; Waxman \& Markow, 1995). However, this research has focused almost exclusively on names for objects. Based on Gentner's $(1981,1982)$ relational relativity argument that verbs and other relational terms are more linguistically shaped than are concrete noun categories, we speculate that the influence of language and labels may be much greater for relational concepts than for common object categories.

Our investigations support the claim that learning relational category names can serve to highlight relational structure. Experience labeling and categorizing the figures used in the study helped children to recognize the higher-order commonalities shared by the figures. It is worth noting that the amount of language training was rather modest: Children sorted eight instances and four 


\section{Kotovsky and Gentner}

noninstances of each pattern, and the experimenter provided the label if the child could not. Nonetheless, the evidence from Experiment 3 suggests that language can facilitate attention to common relational structure.

Additional research likewise suggests that language may be an important pathway to learning to think relationally. Smith and Sera (1992) gave children aged 2 through 5 a cross-dimensional triads task in which they had to decide, for example, whether a dark mouse matched with a big mouse or with a small mouse. They found that children's mapping preferences changed developmentally, and further that their preferences on a verbal version of the task, using the names of the dimensions, appeared to lead their preferences on a nonverbal perceptual matching task by 1 or 2 years. This suggested an influence of dimensional language on the development of dimensional structure and cross-dimensional mapping. Rattermann et al. (1989) gave 3-year-olds a mapping task between two triads of objects monotonically decreasing in size (see also Gentner \& Rattermann, 1991; Gentner et al., 1995). The children had to say which object in their set corresponded to a designated object in the experimenter's set, using a "same-relativesize" rule (e.g., choose the largest object in the set). The task was quite difficult, due to extraneous object similarities (crossmappings) that competed with the relational mapping. For example, the experimenter's small, medium, and large objects might be a car, cup, and house, and the child's small, medium, and large objects an identical cup, an identical house, and a flower pot. Thus, when the largest object was designated in the experimenter's set (the house), the child had to pass over the house in his or her set and choose the flower pot. Even with corrective feedback, 3-year-olds were at chance on this task. However, when they were taught to use relational labels for the three objects (e.g., "Daddy, Mommy, Baby" or "big, little, tiny") they were able to learn the correct mapping, and even to transfer to new sets of objects.

These results suggest that the acquisition of relational language may promote the recognition of abstract relational similarity and the development of relational categories (Gentner \& Medina, 1966; Gentner \& Rattermann, 1991; Premack, 1983; Vygotsky, 1962). Additional research might investigate the effect of more intensive training on the relational labels (e.g., training to a criterion), the longevity of such effects, and the gener- alizability of such relational language to other situations.

\section{Concluding Comments}

Our goal in this research was to study the learning processes by which children come to appreciate relational categories. Therefore we must ask whether this learning persists beyond the immediate session and whether these processes bear any resemblance to processes occurring in the real world. On the first point we have some evidence from the follow-up study to Experiment 1 that the gains made from aligning the more concrete triads can endure for at least a few days. In this study, 4-year-olds showed a transfer effect from the Same-polarity to the Opposite-polarity trials in spite of the fact that the Opposite-polarity trials were presented roughly 2 days after the Samepolarity trials. Further, Rattermann and Gentner (1996) have found retention over several weeks of the relational learning in their "Daddy, Mommy, Baby" mapping task described above.

A second issue is whether these kinds of comparison processes occur in children's natural processing. There is anecdotal evidence that they do. Dan Slobin (personal communication, April 1986) reports a spontaneous example from his daughter, Heida, then a well-traveled 3-year-old. One day in Turkey she heard a dog barking and remarked, "Dogs in Turkey make the same sound as dogs in America. . . . Maybe all dogs do. Do dogs in India sound the same?" For Heida to arrive at this question, she had to have compared dogs from different countries and noted that they sound the same. But the comparison goes further, for Slobin noted in his journal, "She apparently noticed that while the people sounded different from country to country, the dogs did not." Thus Heida must also have compared people from different countries and noted that they typically sound different (speak different languages); and, finally, she must have aligned these two comparisons to draw the contrast, "As you go from country to country, people sound different but dogs sound the same." Thus her own experiential comparisons led her to a deep question about the difference between human language and animal sounds.

Our findings support progressive alignment and re-representation as mechanisms by which children may come to recognize abstract relational similarity and form relational categories. We further suggest that 


\section{Child Development}

progressive alignment takes place naturally and spontaneously as children make similarity comparisons. It can be promoted by concerted experience and by the use of common labels to call attention to the relational commonalities. The process of making simple comparisons may be a path toward finding richer and deeper commonalities.

\section{References}

Billow, R. M. (1975). A cognitive developmental study of metaphor comprehension. Developmental Psychology, 11, 415-423.

Brown, A. L. (1989). Analogical leaming and transfer: What develops? In S. Vosniadou \& A. Ortony (Eds.), Similarity and analogical reasoning (pp. 369-412). New York: Cambridge University Press.

Brown, A. L., \& DeLoache, J. S. (1978). Skills, plans, and self-regulation. In R. S. Siegler (Ed.), Children's thinking: What develops? (pp. 3-35). Hillsdale, NJ: Erlbaum.

Brown, A. L., Kane, M. J., \& Echols, C. H. (1986). Young children's mental models determine analogical transfer across problems with a common goal structure. Cognitive Development, 1, 103-121.

Bryant, P. E. (1974). Perception and understanding in young children: An experimental approach. New York: Basic.

Bryant, P. E., \& Trabasso, T. (1971). Transitive inference and memory in young children. $\mathrm{Na}$ ture, 232, 456-458.

Burstein, M. H. (1983). Concept formation by incremental analogical reasoning and debugging. Proceedings of the International $\mathrm{Ma}$ chine Learning Workshop (pp. 19-25). Urbana: University of Illinois.

Carey, S. (1985). Conceptual change in childhood. Cambridge, MA: MIT Press.

Carey, S. (1991). Knowledge acquisition: Enrichment or conceptual change? In S. Carey \& R. Gelman (Eds.), The epigenesis of mind: Essays on biology and cognition (pp. 257-291). Hillsdale, NJ: Erlbaum.

Case, R. (1987). The structure and process of intellectual development. Special Issue: The neoPiagetian theories of cognitive development: Toward an integration. International Journal of Psychology, 22(5-6), 571-607.

Chen, Z., \& Daehler, M. W. (1989). Positive and negative transfer in analogical problem solving by 6-year-old children. Cognitive Development, 4, 327-368.

Chi, M. T. H. (1981). Knowledge development and memory performance. In M. Friedman, J. P. Das, \& N. O'Conner (Eds.), Intelligence and learning (pp. 221-230). New York: Plenum.
Chi, M. 'T. H., Feltovich, P. J., \& Glaser, R. (1981). Categorization and representation of physics problems by experts and novices. Cognitive Science, 5, 121-151.

Chipman, S. F., \& Mendelson, M. J. (1979). Influence of six types of visual structure on complexity judgments in children and adults. Journal of Experimental Psychology: Human Perception and Performance, 5, 365-378.

Crisafi, M. A., \& Brown, A. L. (1986). Analogical transfer in very young children: Combining two separately learned solutions to reach a goal. Child Development, 57, 953-968.

DeLoache, J. S. (1987) Rapid change in the symbolic functioning of very young children. Science, 238, 1556-1557.

DeLoache, J. S. (1989). The development of rep resentation in young children. In $\mathbf{H}$. W. Reese (Ed.), Advances in child development and behavior (Vol. 22, pp. 1-39). New York: Academic Press.

DeLoache, J. S. (in press). Early symbol understanding and use. In D. Medin (Ed.), The psychology of learning and motivation (Vol. 32). New York: Academic Press.

Elio, R., \& Anderson, J. R. (1981). The effects of category generalizations and instance similarity on schema abstraction. Journal of Experimental Psychology: Human Learning and Memory, 7, 397-417.

Falkenhainer, B. (1988). Learning from physical analogies: A study of analogy and the explanation process (Tech. Rep. No. UIUCDCS-R88-1479). Urbana: University of Illinois, Department of Computer Science.

Falkenhainer, B. (1990). Analogical interpretation in context. Proceedings of the Twelfth Annual Conference of the Cognitive Science Society (pp. 69-76). Hillsdale, NJ: Erlbaum.

Falkenhainer, B., Forbus, K. D., \& Gentner, D. (1986). The structure-mapping engine. Proceedings of the Fifth National Conference on Artificial Intelligence (pp. 272-277). Los Altos, CA: Morgan Kaufman.

Falkenhainer, B., Forbus, K. D., \& Gentner, D. (1989). The structure-mapping engine: Algorithm and examples. Artificial Intelligence, 41, 1-63.

Foard, C. F., \& Kemler-Nelson, D. G. (1984). Holistic and analytic modes of processing: The multiple determinants of perceptual analysis. Journal of Experimental Psychology: General, 113, 94-111.

Forbus, K. D., \& Gentner, D. (1986). Learning physical domains: Toward a theoretical framework. In R. S. Michalski, J. G. Carbonell, \& T. M. Mitchell (Eds.), Machine learning: An artificial intelligence approach (Vol. 2, pp. 311-348). Los Altos, CA: Kaufmann.

Forbus, K. D., Gentner, D., \& Law, K. (1995). 
MAC/FAC: A model of similarity-based retrieval. Cognitive Science, 19, 141-205.

Forbus, K. D., \& Oblinger, D. (1990). Making SME greedy and pragmatic. Proceedings of the Twelfth Annual Conference of the Cognitive Science Society (pp. 61-68). Hillsdale, NJ: Erlbaum.

Garner, W. R. (1978). Aspects of a stimulus: Features, dimensions, and configurations. In $\mathrm{E}$. Rosch \& B. B. Lloyd (Eds.), Cognition and categorization (pp. 99-133). Hillsdale, NJ: Erlbaum.

Gelman, S. A., \& Markman, E. M. (1987). Young children's inductions from natural kinds: The role of categories and appearances. Child Development, 58, 1532-1541.

Gentner, D. (1977a). Children's performance on a spatial analogies task. Child Development, 48, 1034-1039.

Gentner, D. (1977b). If a tree had a knee, where would it be? Children's performance on simple spatial metaphors. Papers and Reports on Child Language Development, 13, 157-164.

Gentner, D. (1981). Some interesting differences between nouns and verbs. Cognition and Brain Theory, 4, 161-178.

Gentner, D. (1982). Why nouns are learned before verbs: Linguistic relativity versus natural partitioning. In S. Kuczaj (Ed.), Language development: Vol. 2. Language, thought and culture (pp. 301-334). Hillsdale, NJ: Erlbaum.

Gentner, D. (1983). Structure-mapping: A theoretical framework for analogy. Cognitive Science, $7,155-170$.

Gentner, D. (1988). Metaphor as structure mapping: The relational shift. Child Development, 59, 47-59.

Gentner, D. (1989). The mechanisms of analogical learning. In S. Vosniadou \& A. Ortony (Eds.), Similarity and analogical reasoning (pp. 199-241). New York: Cambridge University Press.

Gentner, D. (in press). Individuation, relational relativity, and early word learning. In $\mathrm{M}$. Bowerman \& S. Levinson (Eds.), Conceptual development and language acquisition. Cambridge: Cambridge University Press.

Gentner, D., Brem, S., Ferguson, R., Markman, A., Levidow, B. B., Wolff, P., \& Forbus, K. D. (in press). Conceptual change via analogical reasoning: A case study of Johannes Kepler. Journal of Learning Sciences.

Gentner, D., \& Markman, A. B. (1993). AnalogyWatershed or Waterloo? Structural alignment and the development of connectionist models of cognition. In S. J. Hanson, J. D. Cowan, \& C. L. Giles (Eds.), Advances in neural information processing systems (Vol. 5, pp. 855862). San Mateo, CA: Kauffman.

Gentner, D., \& Markman, A. B. (1995). Analogy- based reasoning and connectionism. In M. Arbib (Ed.), The handbook of brain theory and neural networks. Cambridge, MA: MIT Press.

Gentner, D., \& Markman, A. B. (in press). Structure-mapping in analogy and similarity. American Psychologist.

Gentner, D., \& Medina, J. (1996). Comparison and the development of cognition. Manuscript submitted for publication.

Gentner, D., \& Rattermann, M. J. (1991). Language and the career of similarity. In S. A. Gelman \& J. P. Byrnes (Eds.), Perspective on thought and language: Interrelations in development (pp. 225-277). New York: Cambridge University Press.

Gentner, D., Rattermann, M. J., \& Campbell, R. (1996). Evidence for a relational shift in the development of analogy: A reply to Goswami and Brown. Manuscript submitted for publication.

Gentner, D., Rattermann, M. J., \& Forbus, K. D. (1993). The roles of similarity in transfer: Separating retrievability and inferential soundness. Cognitive Psychology, 25, 524-575.

Gentner, D., Rattermann, M. J., Markman, A. B., \& Kotovsky, L. (1995). Two forces in the development of relational similarity. In T. J. Simon \& G. S. Halford (Eds.), Developing cognitive competence: New approaches to process modeling (pp. 263-313). Hillsdale, NJ: Erlbaum.

Gentner, D., \& Toupin, C. (1986). Systematicity and surface similarity in the development of analogy. Cognitive Science, 10, 277-300.

Gentner, D., \& Wolff, P. (in press). Metaphor and knowledge change. In A. Kasher \& Y. Shen (Eds.), Cognitive aspects of metaphor: Studies in linguistics, literature, philosophy and psychology. Amsterdam: North Holland.

Gibbs, R. W., Jr., \& O'Brien, J. E. (1990). Idioms and mental imagery: The metaphorical motivation for idiomatic meaning. Cognition, 36, 35-68.

Gick, M. L., \& Holyoak, K. J. (1980). Analogical problem solving. Cognitive Psychology, 12, 306-355.

Gick, M. L., \& Holyoak, K. J. (1983). Schema inducton and analogical transfer. Cognitive Psychology, 15, 1-38.

Goldstone, R. L. (1994). Similarity, interactive activation, and mapping. Journal of Experimental Psychology: Learning, Memory and Cognition, 20, 3-28.

Goldstone, R. L., \& Medin, D. L. (1994). Similarity, interactive-activation and mapping. In K. J. Holyoak \& J. A. Barnden (Eds.), Advances in connectionist and neural computation theory: Vol. 2. Analogical connections (pp. 321-362). Norwood, NJ: Ablex. 
Goswami, U. (1989). Relational complexity and the development of analogical reasoning. Cognitive Development, 4, 251-268.

Goswami, U. (1991). Analogical reasoning: What develops? A review of research and theory. Child Development, 62, 1-22.

Goswami, U. (1992). Analogical reasoning in children. Hillsdale, NJ: Erlbaum.

Goswami, U., \& Brown, A. L. (1989). Melting chocolate and melting snowmen: Analogical reasoning and causal relations. Cognition, $\mathbf{3 5}$, 69-95.

Halford, G. S. (1987). A structure-mapping approach to cognitive development. Special Issue: The neo-Piagetian theories of cognitive development: Toward an interpretation. International Journal of Psychology, 22(5-6), 609-642.

Halford, G. S. (1992). Analogical reasoning and conceptual complexity in cognitive development. Human Development, 35, 193-218.

Halford, G. S. (1993). Children's understanding: The development of mental models. Hillsdale, NJ: Erlbaum.

Halford, G. S., Wilson, W. H., Guo, J., Gayler, R. W., Wiles, J., \& Stewart, J. E. M. (1995). Connectionist implications for processing capacity limitations in analogies. In K. J. Holyoak \& J. Barnden (Eds.), Advances in connectionist and neural computation theory: Vol. 2. Analogical connections (pp. 363-415). Norwood, NJ: Ablex.

Hayes-Roth, F., \& McDermott, J. (1978). An interference matching technique for inducing $a b$ stractions. Communications of the ACM, 21, 401-411.

Holyoak, K. J., \& Thagard, P. (1989). A computational model of analogical problem solving. In S. Vosniadou \& A. Ortony (Eds.), Similarity and analogical reasoning (pp. 242-266). New York: Cambridge University Press.

Imai, M., \& Gentner, D. (1993). Linguistic relativity vs. universal ontology: Cross-linguistic studies of the object/substance distinction. Proceedings of the Chicago Linguistic Society.

Karmiloff-Smith, A. (1991). Beyond modularity: Innate constraints and developmental change. In S. Carey \& R. Gelman (Eds.), The epigenesis of mind: Essays on biology and cognition (pp. 171-198). Hillsdale, NJ: Erlbaum.

Karmiloff-Smith, A. (1992). Beyond modularity: A developmental perspective on cognitive science. Cambridge, MA: MIT Press.

Kass, A. (1989). Adaptation-based explanation: Explanation as cases. In A. M. Segre (Ed.), Proceedings of the Sixth International Workshop on Machine Learning (pp. 49-51). San Mateo, CA: Kaufmann.

Kass, A., \& Leake, D. (1987). A case-based ap- proach to building explanations for explanation-based learning. Unpublished manuscript, Department of Computer Science, Yale Universty, New Haven, CT.

Kolodner, J. L., \& Simpson, R. L. (1989). The MEDIATOR: Analysis of an early case-based problem solver. Cognitive Science, 13, 507-549.

Krumhans1, C. L. (1978). Concerning the applicability of geometric models to similarity data: The interrelationship between similarity and spatial density. Psychological Review, 85, $445-463$.

Lakoff, G. (1987). Women, fire and dangerous things: What categories reveal about the mind. Chicago: University of Chicago Press.

Lakoff, G., \& Johnson, M. (1980). The metaphorical structure of the human conceptual system. Cognitive Science, 4, 195-208.

Markman, A. B., \& Gentner, D. (1993). Structural alignment during similarity comparisons. Cognitive Psychology, 23, 431-467.

Markman, E. M. (1989). Categorization in children: Problems of induction. Cambridge, MA: MIT Press.

Markman, E. M., \& Hutchinson, J. E. (1984). Children's sensitivity to constraints on word meaning: Taxonomic versus thematic relations. Cognitive Psychology, 16, 1-27.

Marzolf, D. P., \& DeLoache, J. S. (1994). Transfer in young children's understanding of spatial representations. Child Development, 65, $1-15$.

McCawley, J. D. (1968). The role of semantics in a grammar. In E. Bach \& R. T. Harms (Eds.), Universals in linguistic theory (pp. 125-169). New York: Holt, Reinhart \& Winston.

McCawley, J. D. (1972). Kac and Shibatani on the grammar of killing. In J. P. Kimball (Ed.), Syntax and semantics (Vol. 1). New York: Seminar.

Medin, D. L., Goldstone, R. L., \& Gentner, D. (1993). Respects for similarity. Psychological Review, 100(2), 254-278.

Medin, D. L., \& Koss, B. H. (1989). The specific character of abstract thought: Categorization, problem-solving, and induction. In R. $J$. Stemberg (Ed.), Advances in the psychology of human intelligence (Vol. 5, 189-223). Hillsdale, NJ: Erlbaum.

Namy, L. L., Smith, L. B., \& Gershkoff-Stowe, L. (in press). Young children's discovery of spatial classification. Cognitive Development.

Norman, D. A., \& Rumelhart, D. E. (1975). Explorations in cognition. San Francisco: Freeman.

Novick, L. R. (1988). Analogical transfer, problem similarity, and expertise. Journal of Experimental Psychology: Learning, Memory, and Cognition, 14, 510-520.

Novick, L. R., \& Holyoak, K. J. (1991). Mathemati- 
cal problem solving by analogy. Journal of $E x-$ perimental Psychology: Learning, Memory, and Cognition, 17, 398-415.

Ortony, A., Reynolds, R. E., \& Arter, J. A. (1978). Metaphor: Theoretical and empirical research. Psychological Bulletin, 85, 919-943.

Palmer, S. E. (1975). Visual perception and world knowledge: Notes on a model of sensorycognitive interaction. In D. A. Norman, D. E. Rumelhart, \& The LNR Research Group (Eds.), Explorations in cognition (pp. 279307). San Francisco: Freeman.

Pears, R., \& Bryant, P. (1989). Transitive inferences in young children about spatial position. British Journal of Psychology, 81, 497-510.

Piaget, J., Montangero, J., \& Billeter, J. (1977). La formation des correlats. In J. Piaget (Ed.), L'Abstraction reflechissante (pp. 115-129). Paris: Presses Universitaires de France.

Premack, D. (1983). The codes of man and beasts. Behavioral \& Brain Sciences, 6, 125-167.

Rattermann, M. J., \& Gentner, D. (1996). Use of relational language improves children's performance on an analogy task. Manuscript in preparation.

Rattermann, M. J., Gentner, D., \& DeLoache, J. (1989, April). Effects of competing surface similarity on children's performance in an analogical task. Poster presented at the biennial meeting of the Society for Research in Child Development, Kansas City, MO.

Ross, B. H. (1984). Remindings and their effects in learning a cognitive skill. Cognitive Psychology, 16, 371-416.

Ross, B. H. (1989). Remindings in learning and instruction. In S. Vosniadou \& A. Ortony (Eds.), Similarity and analogical reasoning (pp. 438-469). New York: Cambridge University Press.

Rovee-Collier, C. K., \& Fagen, J. W. (1981). The retrieval of memory in early infancy. In L. P. Lipsett (Ed.), Advances in infancy research (Vol. 1, pp. 225-254). Norwood, NJ: Ablex.

Schank, R. C., \& Abelson, R. P. (1977). Scripts, plans, goals, and understanding: An inquiry into human knowledge structures. Hillsdale, NI: Erlbaum.

Schank, R. C., \& Leake, D. (1989). Creativity and learning in a case-based explainer. Artificial Intelligence, 40, 353-385.

Schumacher, R. M. (1988). Some determinants of analogical reminding. Unpublished doctoral dissertation, University of Illinois, Champaign-Urbana.

Shepp, B. E. (1978). From perceived similarity to dimensional structure: A new hypothesis about perceptual development. In E. Rosch \& B. B. Lloyd (Eds.), Cognition and categorization (pp. 135-167). Hillsdale, NJ: Erlbaum.
Smith, L. B. (1984). Young children's understanding of attributes and dimensions: A comparison of conceptual and linguistic measures. Child Development, 55, 363-380.

Smith, L. B. (1989). From global similarities to kinds of similarities: The construction of dimensions in development. In S. Vosniadou \& A. Ortony (Eds.), Similarity and analogical reasoning (pp. 146-178). New York: Cambridge University Press.

Smith, L. B. (1993). The concept of same. In H. W. Reese (Ed.), Advances in child development and behavior (Vol. 24, pp. 216-252). San Diego: Academic Press.

Smith. L. B., \& Kemler, D. G. (1977). Developmental trends in free classification: Evidence for a new conceptualization of perceptual development. Journal of Experimental Child Psychology, 24, 279-298.

Smith, L. B., \& Sera, M. D. (1992). A developmental analysis of the polar structure of dimensions. Cognitive Psychology, 24, 99142.

Thorndike, E. L. (1903). Educational psychology. New York: Lemcke \& Buechner.

Tighe, T. J., \& Tighe, L. S. (1968). Perceptual learning in the discrimination processes of children: An analysis of five variables in perceptual pretraining. Journal of Experimental Psychology, 77, 125-134.

Turner, M. (1987). Death is the mother of beauty: Mind, metaphor, and criticism. Chicago: University of Chicago Press.

Tumer, M. (1991). Reading minds: The study of English in the age of cognitive science. Princeton, NJ: Princeton University Press.

Tyrrell, D. J., Stauffer, L. B., \& Snowman, L. G. (1991). Perception of abstract identity/difference relationships by infants. Infant Behavior and Development, 14, 125-129.

Uttal, D. H., \& DeLoache, J. S. (1995, April). Seeing through symbols? Children's developing understanding of graphic and linguistic representations of space: Moving beyond theoretical clashes. Paper presented at the biennial meetings of the Society for Research in Child Development, Indianapolis, IN.

Uttal, D. H., Schreiber, J. C., \& DeLoache, J. S. (1995). Waiting to use a symbol: The effects of delay on children's use of models. Child Development, 66, 1875-1889.

Vosniadou, S. (1987). Children and metaphors. Child Development, 58, 870-885.

Vosniadou, S. (1989). Analogical reasoning as a mechanism in knowledge acquisition: A developmental perspective. In S. Vosniadou \& A. Ortony (Eds.), Similarity and analogical reasoning (pp. 413-437). New York: Cambridge University Press.

Vygotsky, L. (1962). Thought and language. Cam- 


\section{Child Development}

bridge, MA: MIT Press. (Original work published 1934).

Waxman, S. (1991). Convergences between semantic and conceptual organization in the preschool years. In S. A. Gelman \& J. P. Byrnes (Eds.), Perspectives on language and thought: Interrelations in development (pp. 107-145). London: Cambridge University Press.

Waxman, S., \& Gelman, R. (1986). Preschoolers' use of superordinate relations in classification and language. Cognitive Development, 1, 139-156.

Waxman, S. R., \& Hall, D. G. (1993). The development of a linkage between count nouns and object categories: Evidence from fifteen- to twenty-one-month-old infants. Child Development, 64, 1224-1241.

Waxman, S., \& Markow, D. G. (1995). Words as invitations to form categories: Evidence from 12-month-old infants. Cognitive Psychology, 29, 257-302.

Winner, E., Rosenstiel, A. K., \& Gardner, H. (1976). The development of metaphoric understanding. Developmental Psychology, 12, 289-297.

Zwislocki, J. J., \& Goodman, D. A. (1980). Absolute scaling of sensory magnitudes: A validation. Perception and Psychophysics, 28, 28-38. 
This document is a scanned copy of a printed document. No warranty is given about the accuracy of the copy. Users should refer to the original published version of the material. 